\title{
Author Correction: Intra- and intermolecular self-assembly of a 20-nm-wide supramolecular hexagonal grid
}

Zhe Zhang, Yiming LiD, Bo Song (D), Yuan Zhang (iD, Xin Jiang, Ming Wang, Ryan Tumbleson, Changlin Liu (D, Pingshan Wang, Xin-Qi Hao, Tomas Rojas, Anh T. Ngo, Jonathan L. Sessler (D), George R. Newkome, Saw Wai Hla and Xiaopeng Li (iD

Correction to: Nature Chemistry https://www.nature.com/articles/s41557-020-0454-z, published online 13 April 2020.

In the version of this Article originally published, author Ryan Tumbleson's surname was misspelled as 'Trumbleson'. This has been corrected in the online versions of this Article and in the Supplementary Information.

Published online: 14 May 2020

https://doi.org/10.1038/s41557-020-0486-4

๑) The Author(s), under exclusive licence to Springer Nature Limited 2020

\section{Publisher Correction: Food for thought}

\section{Bruce C. Gibb}

Correction to: Nature Chemistry https://doi.org/10.1038/s41557-020-0459-7, published online 16 April 2020.

In the version of this Thesis originally published, an oxygen atom was missing from the structure of coenzyme A (CoA). This has now been corrected in the online versions of this Thesis.

Published online: 6 May 2020

https://doi.org/10.1038/s41557-020-0480-x

(c) The Author(s), under exclusive licence to Springer Nature Limited 2020

\section{Publisher Correction: The rise of preprints in chemistry}

\section{François-Xavier Coudert}

Correction to: Nature Chemistry https://doi.org/10.1038/s41557-020-0477-5, published online 18 May 2020.

In the version of this Comment originally published, author François-Xavier Coudert was incorrectly given an additional affiliation. The correct affiliation for the author is 'Chimie ParisTech, PSL University, CNRS, Institut de Recherche de Chimie Paris, Paris, France'. This has been corrected in online versions of this Comment.

Published online: 21 May 2020

https://doi.org/10.1038/s41557-020-0492-6

(c) The Author(s), under exclusive licence to Springer Nature Limited 2020 